\title{
AN INVESTIGATION ON THE POTENTIAL OF EXTRACTING NATURAL DYES FROM BEETROOT AND TURMERIC
}

\author{
Sindra L Summoogum-Utchanah ${ }^{1}$, Hashita Joyram ${ }^{2}$ \\ ${ }^{1}$ Lecturer, Chemical and Environmental Engineering Department, University of Mauritius, Reduit, Mauritius \\ ${ }^{2}$ Student, Chemical and Environmental Engineering Department, University of Mauritius, Reduit, Mauritius
}

\begin{abstract}
Today, owing to the environmental and health drawbacks associated with synthetics dyes, stringent standards are imposed by many countries including Mauritius. Following this issue, great enthusiasm is evoked in the rival of natural colourants which are nowadays gaining popularity due to their green approach. Two well-known, readily available and low cost natural dyes bearing plants in Mauritius namely beetroot (Beta Vulgaris) and turmeric (Curcuma Longa) were opted in this study. A comparative study between the extraction of betalains and curcuminoids from the two plants were systematically evaluated between conventional magnetic stirring (MS) and novel microwave assisted extraction techniques (MAE). The optimum operating conditions to yield maximum hues from the two plant species were $50 \%$ aqueous ethanol, agitation speed of $160 \mathrm{rpm}$, microwave power of $320 \mathrm{~W}$, particle sizes of $0.45 \mathrm{~mm}$ and a solid to solvent ratio (SSR) of 1/35. Under the optimised conditions, the results demonstrated that the extraction yields for MAE were higher and more efficient than the conventional one. Consequently, for MS extraction of beetroot and turmeric, the maximum yields recovered were $69.55 \%$ and $48.00 \%$, whilst the yield for MAE extraction rose to $89.64 \%$ and $79.73 \%$ respectively. Using the experimental data, this research also explored Peleg's and Elovich's kinetic models of dyes extraction.
\end{abstract}

Keywords: Beetroot, Turmeric, Magnetic stirring, Microwave, Extraction $* * *$

\section{INTRODUCTION}

Since immemorial time, natural colours are of paramount importance in dyestuff products but have drastically disappeared owing to the evolution of synthetic dyes [1]. The exploitation of colours cannot be halted, because consumers always demand coloured products for eyeappeal, decoration and for aesthetic purposes [2]. However, due to the significant environmental and detrimental health risks linked with the processing of synthetic dyes, the world is presently shifting towards the use of green dyes [3]. The latter can be regarded as a viable alternative since they are biodegradable, non-carcinogenic, and emanate low allergic and toxic effects $[3,4]$.

The application of natural dyes in the food and textile arena can be adopted in small developing island like Mauritius, which is richly endowed with a vast variety of natural flora. The non-toxic nature of these dyes and the fact that the plants are easily accessible implies the need for developing and marketing them as viable substitutes for the synthetic dyes found on the local market. Two widely available plants in Mauritius namely beetroot and turmeric were chosen for this study.

Red beetroot, Beta vulgaris belong to the Chenopodiaceae family [5]. The main pigment found in beetroot is recognised as betalain and is one of the richest sources of betanin pigment, which is used for imparting a desirable red color [6]. On the other hand, turmeric, Curcuma Longa is a member of the Zingiberaceae family and forms part of the Curcuminoid family which provides a desired yellow colour
[6]. These plants were selected as they exhibit pharmacological properties like powerful antioxidants, antiinflammatory, good antiviral, antimicrobial activities and anti-carcinogenic activities [7]. Natural dyes extracted from beetroot and turmeric can be a substitute to red and yellow textile dyes since they are readily available, eco-friendly, biodegradable and pose no human and environmental harms.

This knowledge will not only compensate for the health of Mauritian but also create awareness for the environment as a sustainable source of dyes for the local food and textile industries. Besides, abundance of wastes is contributed by industries such as food and beverages which generate huge amount of bio-wastes such as vegetables and fruit peels. Hence, these wasted parts can be fully exploited for extraction of dyes and their application in industries for replacing their synthetic counterparts. Consequently, production of natural dyes needs to be boosted to fulfill the demand of the market and reduce the waste disposal issues.

The research work emphasises on the extraction and kinetic modeling of natural dyes by MS and MAE techniques. As compared to other solid-liquid extraction (SLE) methods, MAE is an innovative and high speed extraction technology which has attracted a lot of attention owing to its unique heating mechanism, safety aspects, simplicity, economic benefits and good performance [8]. Besides, in MAE, the analysis time is curtailed and the analysis time is lowered, thereby generating higher yields [9]. 
Moreover, few studies have been done in Mauritius on the extraction of natural dyes from widely available plants such beetroot and turmeric. In this study, we analysed the optimum conditions for highest yield of the two chosen plants as well as the influence of process parameters such as solvent ratio, particle size, microwave power for MS and MAE processes. The Peleg's and Elovich's kinetic models of dyes extraction were also investigated using the experimental data.

\section{MATERIALS AND METHODS}

\subsection{Preparation of Natural Dye Materials}

Commercially available natural dye bearing plant materials, beetroot and turmeric, cultivated in agricultural land in the Southern part of Mauritius were procured from vegetable market and own territorial garden. The roots and rhizomes of the plant materials were isolated from their leaves and stems, peeled and washed with distilled water to remove any adhering soil, dust and impurities. The latter were then dried and stored in the refrigerator at a low temperature of 4 ${ }^{\circ} \mathrm{C}$ to avoid degradation of pigments prior to extraction. Using four different kitchen grater slot dimensions, the prepared plants parts were finely and homogeneously grated with average particle sizes of thickness of $1.69 \mathrm{~mm}, 1.42$ $\mathrm{mm}, 0.815 \mathrm{~mm}$ and $0.45 \mathrm{~mm}$ which were measured by a calibrated vernier caliper. Each particle size was labeled, closely sealed in four separate containers and stored in the refrigerator for future experiments.

\subsection{Determination of Optimum Wavelength}

$30 \mathrm{~g}$ of smoothly and evenly grated beetroot and turmeric of average particle size of $0.45 \mathrm{~mm}$ were respectively soaked in $300 \mathrm{~mL}$ beaker consisting of $50 \%$ analytical grade ethanol solution and stored in the refrigerator for 3 days. The concentrated dye solution mixture was then diluted 4, 6 , 8 and 10 times. $10 \mathrm{~mL}$ aliquot of each diluted dye solution was then dispensed into separate, well cleaned- dried spectrophotometer glass tubes that were positioned singly into the DR/2500 Hach spectrophotometer to measure absorbance. A glass tube filled with distilled water was initially fitted in the spectrometer machine for zeroing the machine prior to the insertion of each tube. The absorbance of the diluted solutions for both pigments was read for wavelengths varying from $400-650 \mathrm{~nm}$. From experimental results, the wavelengths corresponding to the uppermost absorbance value were recorded. Graph of absorbance against wavelength was eventually plotted from which the optimum wavelengths for beetroot and turmeric dyes were each observed.

\subsection{Plotting the Standard Calibration Curve}

The standard calibration curve was established by recording the absorbance of the above diluted solutions from the spectrophotometer at the pre-observed optimum wavelength. A graph of absorbance against dye concentration was drawn to obtain the calibration curve. The concentration of the diluted solution was evaluated spectrometrically according to Beer-Lambert law equation:
$\mathrm{C}=\mathrm{A} / \mathrm{eL}$

Where: $\mathrm{C}=$ Concentration of dye in the solution, $\mathrm{mol} / \mathrm{L}$

$\mathrm{A}=$ Absorption value

$\mathrm{L}=$ Path length which equals to the diameter of the glass spectrophotometer tube, $1.5 \mathrm{~cm}$

$\mathrm{e}=$ Molar extinction coefficient of dye, $\mathrm{L} / \mathrm{mol} . \mathrm{cm}$

\subsection{Parametric Range for Experiments}

The variation of five principal parameters which were investigated to optimise the operating conditions for achieving maximum extraction yields are presented in table 1. These parameters were varied one at a time to identify the optimum conditions for further experimental runs.

Table 1: Set of Values used for Experimental Runs

\begin{tabular}{|l|l|}
\hline Parameter & Selected values \\
\hline $\begin{array}{l}\text { Ethanol }- \text { water solvent } \\
\text { compositions, EtOH /DW, ml }\end{array}$ & $30 / 70-50 / 50-$ \\
$70 / 30$
\end{tabular}

\subsection{Experimental Procedure for MS and MAE}

To maximise the natural dye extraction yield by MS, the optimum rpm was investigated. Three agitation speed of $120 \mathrm{rpm}, 160 \mathrm{rpm}$ and $200 \mathrm{rpm}$ were varied and the runs were conducted at room temperature for $1 \mathrm{~h}$. The average particle size of the plants and SSR were maintained at 0.45 $\mathrm{mm}$ and $1 / 35$.

The experiments were conducted in a Gallenkamp MS. Depending on the desired SSR $(1 / 15-1 / 20-1 / 25-1 / 30-$ $1 / 35$ ) for the extraction process, corresponding amounts of finely grated plant dimensions were weighted $(2.857 \mathrm{~g}$ $3.333 \mathrm{~g}-4 \mathrm{~g}-5 \mathrm{~g}-6.667 \mathrm{~g}$ ) respectively and delivered into a $300 \mathrm{ml}$ glass beaker constituting a total volume of $100 \mathrm{ml}$ liquid mixture; $50 \mathrm{ml}$ distilled water and $50 \mathrm{ml}$ ethanol. The glass beaker which depicts the extraction vessel was covered using aluminum foil to avert loss of solvent by evaporation and was magnetically stirred for a maximum of $1 \mathrm{~h}$. In all experiments, the agitation speed of $160 \mathrm{rpm}$ was used. After screening through a nylon sieve, filtered extract samples were taken at $10 \mathrm{~min}$ interval and the absorbance was analysed spectrometrically. Eventually, the \% extraction yields were computed.

Before the MAE experiments were performed, the optimal microwave power was investigated at three different powers $(136 \mathrm{~W}-296 \mathrm{~W}-320 \mathrm{~W})$ which were computed as a percentage of the total power input of $800 \mathrm{~W}$. The practicals were carried out at room temperature for $5 \mathrm{~min}$. During this run, other parameters including the optimal $1 / 1$ ethanol - water solvent mixtures, the average particle size of $0.45 \mathrm{~mm}$ and a SSR of 1/35 were kept constant 
MAE was performed in an experimental closed microwave oven (Trust, Model TMW-200M) with a power of $800 \mathrm{~W}$. Typically, a $300 \mathrm{ml}$ glass beaker; representing the extraction vessel constitutes a total of $100 \mathrm{ml}$ solvent volume: $50 \mathrm{ml}$ distilled water and $50 \mathrm{ml}$ ethanol. Weighted amounts $(2.857$ $\mathrm{g}-3.333 \mathrm{~g}-4 \mathrm{~g}-5 \mathrm{~g}-6.667 \mathrm{~g}$ ) of the four grated classes plant sizes equivalent to the selected SSR (1/15 - 1/20 $1 / 25-1 / 30-1 / 35)$ were then subjected to extraction by pouring the solid matrices in the beaker. The glass beaker was situated in the center of the microwave oven, containing a circular, $360^{\circ}$ rotating carousel with several durations of exposure at a constant microwave power of $320 \mathrm{~W}$ which was initially regarded as the optimal one. The beaker was covered with a watch glass to prevent loss of solvent by evaporation. For time duration of only $5 \mathrm{~min}$, dye extracts were retrieved at $50 \mathrm{~s}$ time intervals, just after the mixture in the glass beaker was permitted to cool down to room temperature and filtered through a nylon sieve. Ultimately, using the spectrophotometer, the extract was examined by measuring the absorbance at the optimum wavelength from which the \% dye extraction yield could be evaluated.

\subsection{Computation of Dye Extraction Yield}

The extraction yields of the natural dye bearing plants were formulated regarding the initial weight of dye in the biomass. The concentration of dye present in the extract from both methods was calculated based on the calibration plot after noting the absorbance. The \% natural dye extraction yield was then computed from the following equation proposed by Zhang and Lui [10].

$$
\% \text { Dye Extraction Yield }=\frac{\mathrm{C}_{\mathrm{t}} \times \mathrm{V} \times 100}{\mathrm{w}_{\mathrm{o}}}
$$

Where: $C_{t}=$ Dye concentration in solvent at time $t, \mathrm{mg} / \mathrm{L}$ $\mathrm{V}=$ Total volume of solvent mixed with solid, $\mathrm{mL}$ $\mathrm{W}_{\mathrm{o}}=$ Weight of total dye present in solid plant matrices, $\mathrm{mg}$

\subsection{Kinetic Modeling of Natural Dyes}

Due to the ease of computations of empirical equations, the Peleg's and Elovich's kinetic models were employed in this study to test the suitability of the modeling equations with the experimental results and to further describe betalains and curcuminoids dyes extraction.

\section{MATERIALS AND METHODS}

\subsection{Effect of Time on Extraction Yields for}

\section{Magnetic Stirring and Microwave}

In all experiments conducted, the extraction yields were significantly time dependent and increased with extended extraction times. The effect of each parameter under study as a function of time are discussed in the next sections. The extraction rate is fast at the beginning of the process and reduces as it approaches the saturation level or equilibrium point. Magnetic stirring of natural dyes were performed for $1 \mathrm{hr}$ with sufficient agitation of biomass which was favourable for enhancing the extraction yield as it allowed sufficient swelling of the plant matrix, enlarged the cellular pores and facilitated the leaching of the target analyte [11, 12]. It was observed that maximum dye extraction yields were achieved during the first 20 min thereby only marginal increment with slight increase in colour intensity was observed till the end of the extraction process. The initial sharp increase in the rate of extraction was possibly due to the large concentration gradient between the extracting solvent and the cell as stated by Rakotondramasy, et al [13].

On the other hand, the efficient extraction period for achieving maximum dye yield in MAE was only $5 \mathrm{~min}$. The increasing trend in increase color intensity was more visible in MAE than MS. Figures 1 and 2 below displayed an increase in colour intensity for both extraction methods over time. Although the extraction time is dissimilar in both cases, microwave yields are enormously elevated compared to the classical one. This phenomenon could be explained by the fact that the absorption of microwave energy assisted in the thermal accumulation of the extraction solution, leading to the dissolution of dye into the solution within a short time [14]. However, elongated time exposure in the microwave field was discouraged as a consequence of alteration in the molecular structure and degradation of dye chain molecules exposed at these high temperatures $[15,16]$. Similar effect of microwave irradiation time were also reported in MAE of natural dye from pomegranate rind and flavonoids from traditional Chinese herbs [17, 18]. 


\section{Light to bright colors}

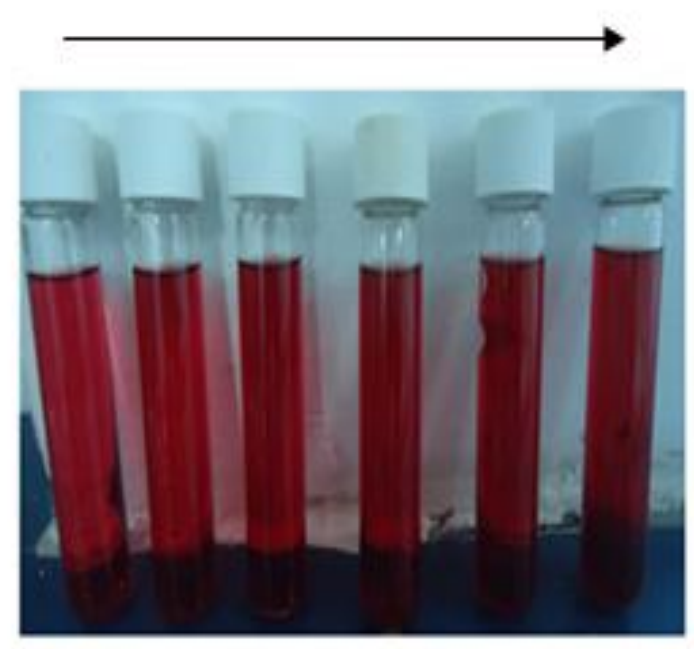

(a)

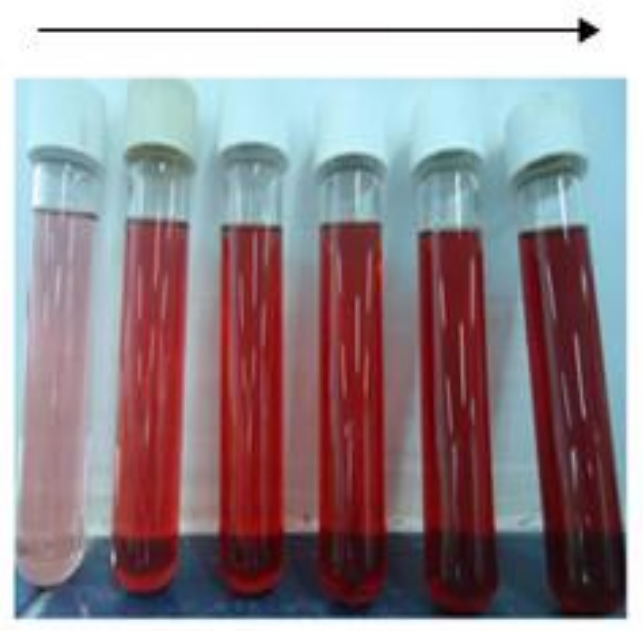

(b)

Fig.1: Increase in Colour Intensity for Beetroot Dye with (a) MS (b) MAE

\section{Light to bright colors}

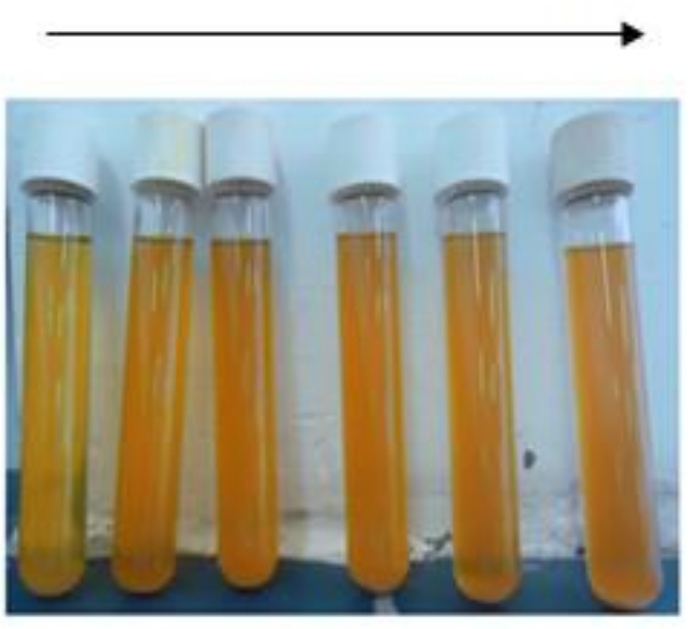

(a)

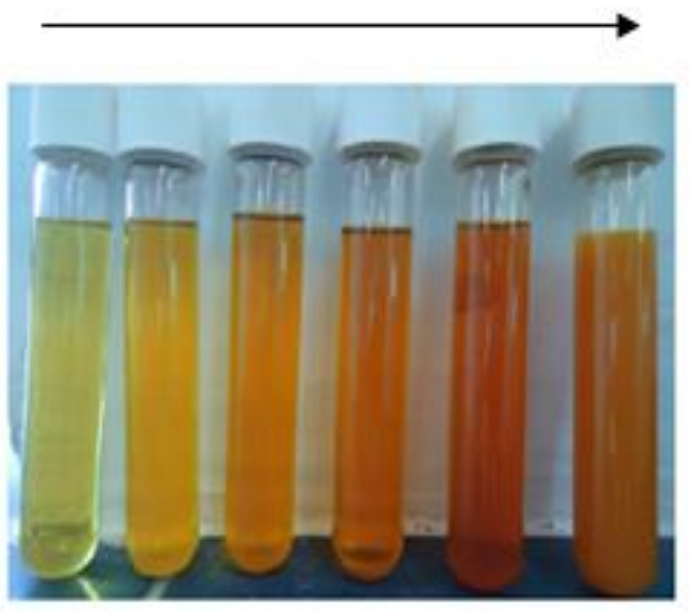

(b)

Fig.2: Increase in Colour Intensity for Turmeric Dye with (a) MS (b) MAE

\subsection{Effect of Extraction Solvent Composition for MS and MAE on Extraction Yields of Betalains and} Curcuminoids

The effect of ethanol - water compositions on extraction yield of betalains and curcuminoids from both extraction methods are portrayed below in Figs. 3 and 4 A microwave power of $320 \mathrm{~W}$, SSR of 1/35 and average particle size of $0.45 \mathrm{~mm}$ were used for the extraction of the pigments during the processes.

During the MS extraction of betalains, we recorded the lowest and highest yield of $35.19 \%$ and $69.19 \%$ at $70 \%$ (v/v) and $50 \%$ (v/v) aqueous ethanol respectively. A similar trend was observed for MAE whereby a yield of $88.34 \%$ and $50.81 \%$ was obtained at $50 \%(\mathrm{v} / \mathrm{v})$ and $70 \%(\mathrm{v} / \mathrm{v})$ ethanol concentration correspondingly. In line with the above, it was inferred that $50 \%$ ethanol was optimal for the extraction of betalains. Identical observation was conformed during the ultrasound-assisted extraction of natural dye from beetroot and its application on leather fabrics [19]. 

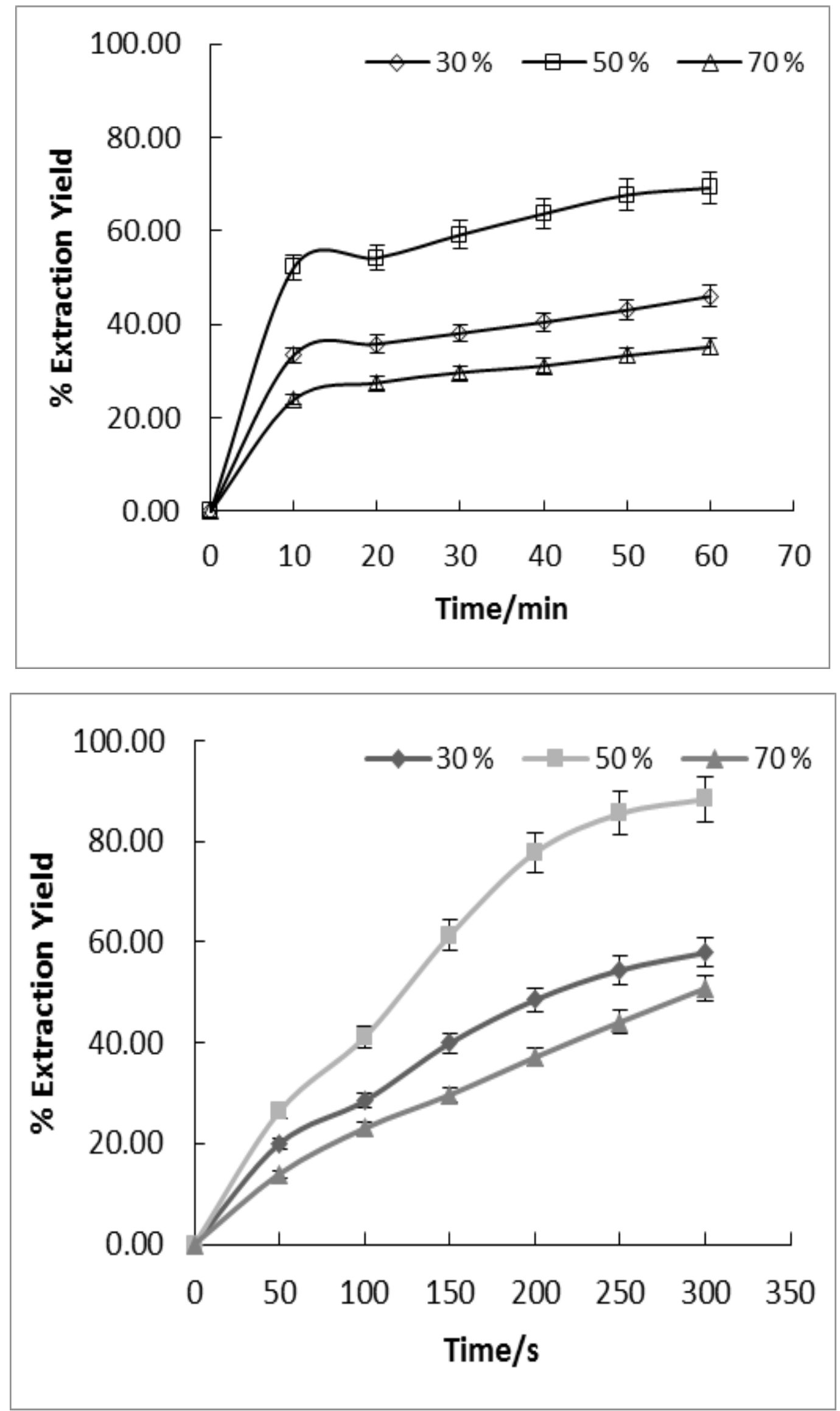

Fig. 3: Effect of Solvent Compositions on Betalains Extraction Yield during MS and MAE at Microwave Power of $320 \mathrm{~W}$, SSR of $1 / 35$ and Particle Size of $0.45 \mathrm{~mm}$ 

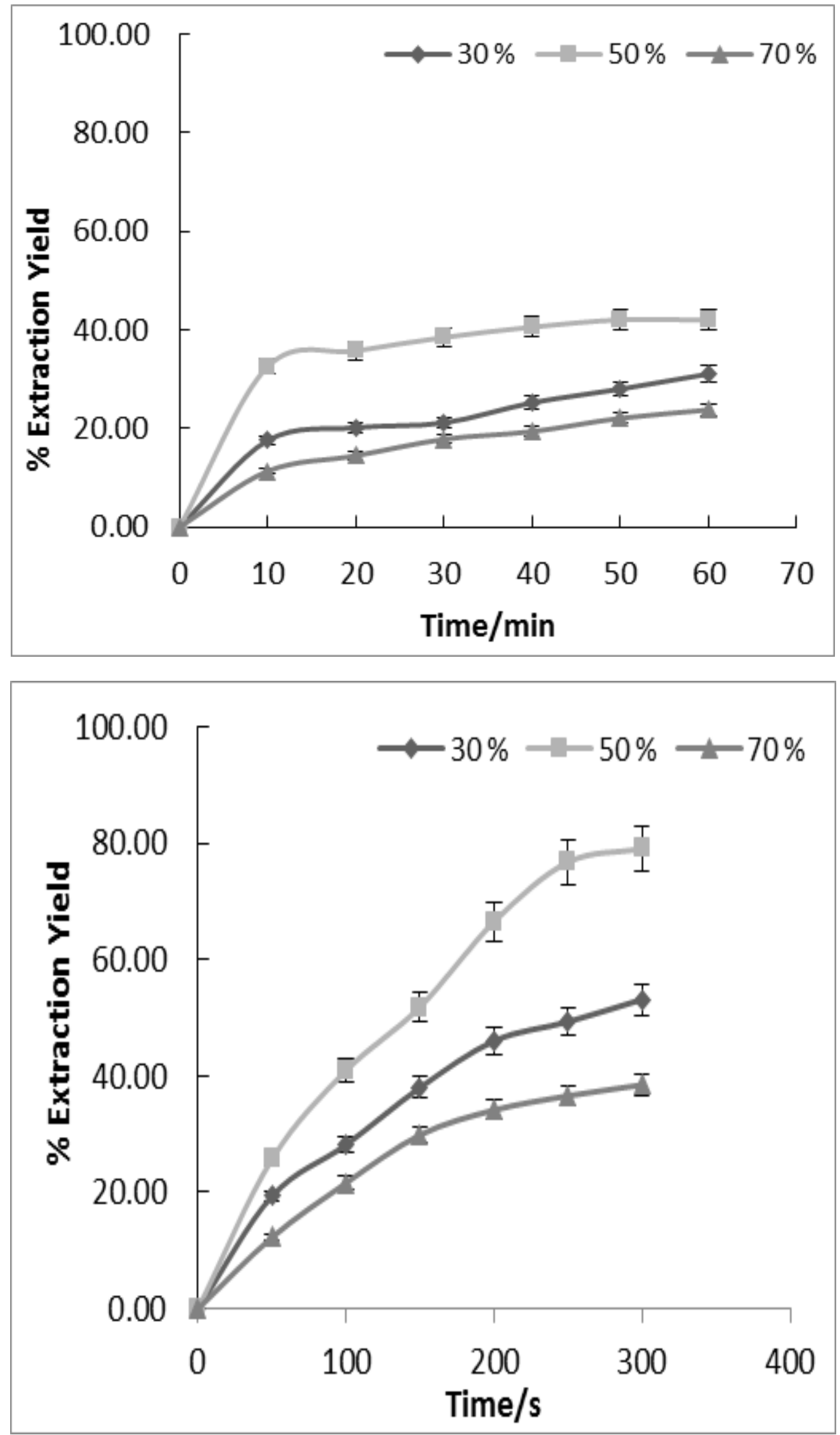

Fig. 4: Effect of Solvent Compositions on Curcuminoids Extraction Yield during MS and MAE at Microwave Power of $320 \mathrm{~W}$, SSR of $1 / 35$ and Particle Size of $0.45 \mathrm{~mm}$ 
Comparable results are obtained for the MS extraction and MAE of curcuminoids. For the former, the yield was greatest at 42.03 $\%$ for $50 \%$ aqueous ethanol and dropped to $23.85 \%$ for $70 \%$ solvent. A significant extraction yield of $79.08 \%$ was attained for $50 \%$ aqueous ethanol while at $70 \%$ ethanol concentration, it fell to a yield of $38.5 \%$ yield for MAE. These results can be attributed to higher solubility of curcuminoids in $50 \%$ ethanol (EtOH) solution which is typically evident in the microwave field. This observation was also in line with previous studies which demonstrated that $50 \%$ ethanol solution was optimal for curcuminoids extraction [20].

As depicted in Figs. 3 and 4, the extraction yields of betalains and curcuminoids from MAE are higher than from MS. In the latter, the extractability of different solvents relied mostly on the solubility of the dyes in the solvent, the mass transfer kinetics, and the potency of the solute/matrix interactions. However, under the influence of microwave, the thermal treatment and the capability to absorbed microwave energy as well as the solvent dielectric properties boosted the extraction efficiency.

The microwave energy has been amplified with the dielectric constant of the molecule, resulting in power dissipated inside the solvent and matrices, generating more effective molecular movement and heating. Being polar solvents, aqueous ethanol/water mixture could efficiently absorb microwave energy, leading to efficient heating and the subsequent improvement in dye extraction yield [21]. By pouring a quantity of water to the mixture, the dielectric constants rose. The values of dielectric constants for various mixture compositions are displayed in table 2. It is notable that although the addition of water into ethanol heightened the mixture dielectric constant, the dissipation factor was diminished as the solvent mixture was unable to absorb microwave energy at such an elevated dielectric constant $[10,21]$. On the basis of this analysis, the mixture constituting of $70 \%$ water is incapable of dissipating the heat as effectively, as shown by the decline in the extraction yield.

\subsection{Effect of MS Agitation Speed on Extraction Yields for Betalains and Curcuminoids}

The influence of agitation speeds on dye extraction yields from both solid matrices is illustrated in Fig. 5(a, b). An extraction yield of $45.19 \%$ for betalains was obtained at $120 \mathrm{rpm}$ while a maximum efficiency of $71.54 \%$ was recorded at an agitation speed of $160 \mathrm{rpm}$. A similar tendency was observed for curcuminoids whereby yields of $19.53 \%$ and $44.36 \%$ were attained at $120 \mathrm{rpm}$ and $160 \mathrm{rpm}$ respectively. Wongkittipong et al. stated that a higher agitation rate of $160 \mathrm{rpm}$ was sufficient to cause a higher mass transfer coefficient and improved convective mass transfer rate, thus facilitating the extraction process [22].

Nevertheless, an elevated agitation rate of $200 \mathrm{rpm}$ exhibited relatively low yields which could be due to physical constraints of the process such as effect of vortex or insufficient contact for solute and solvent interactions [23]. On the other hand, empirical results demonstrated that external mass transfer resistance is negligible at $120 \mathrm{rpm}$ due to poor mixing and excessive load of plant materials on the rotating magnet.

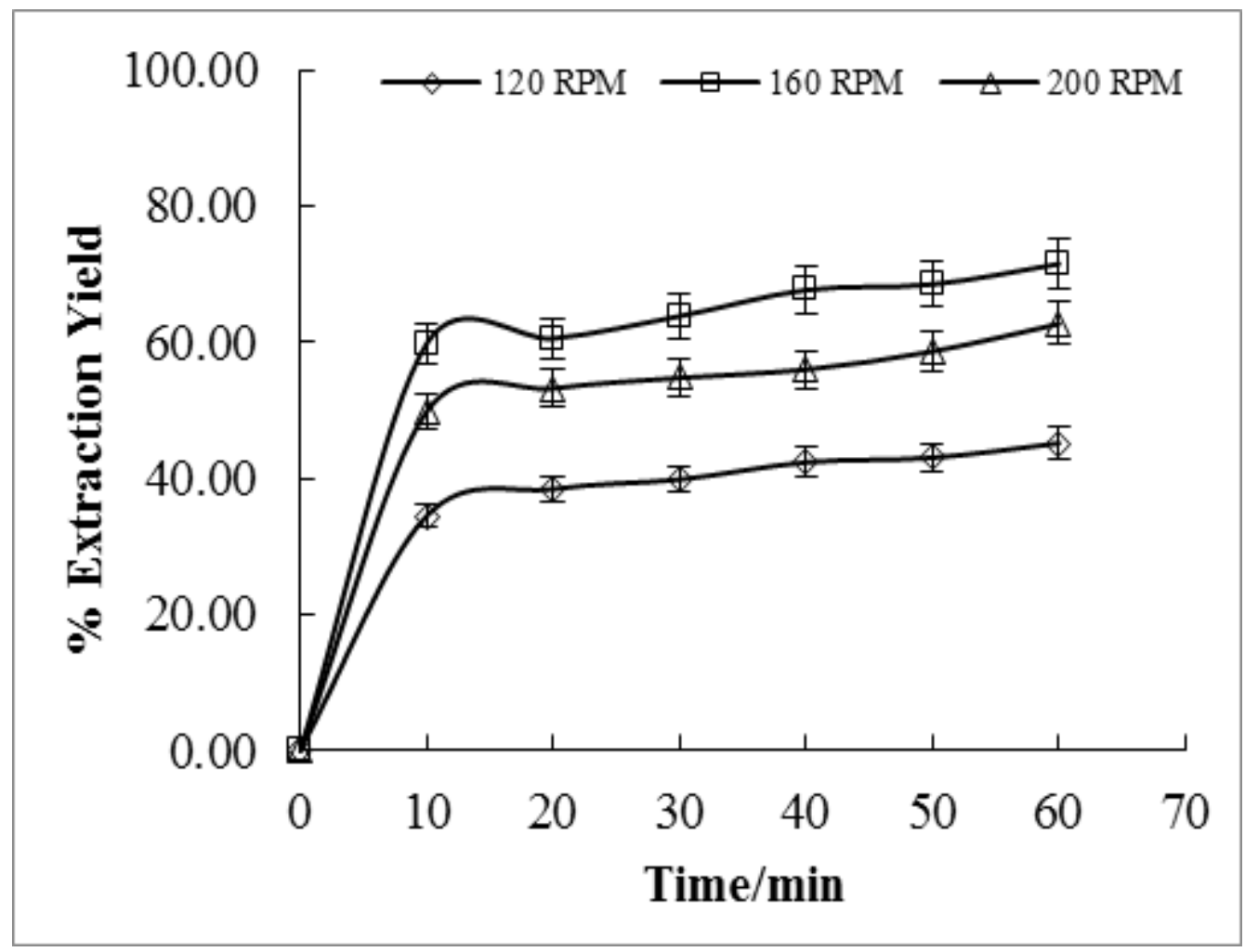




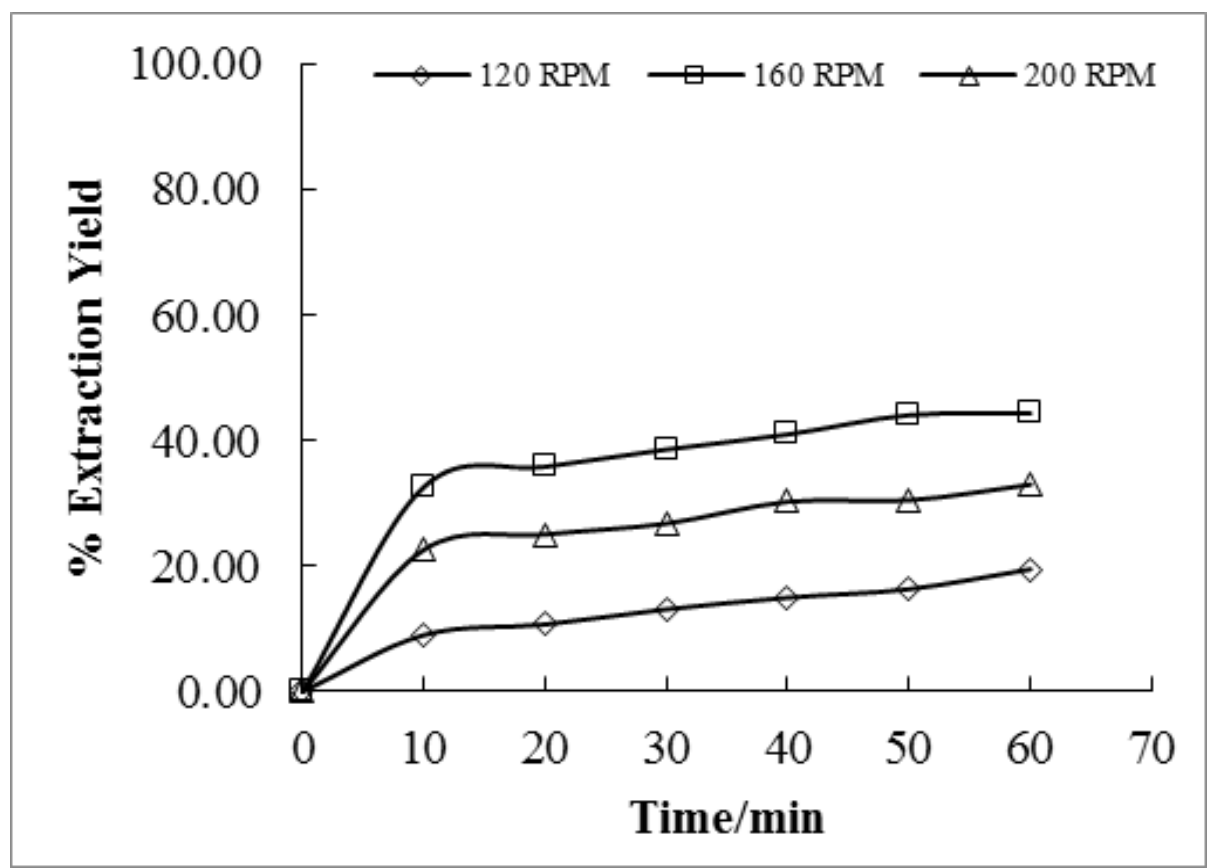

Fig. 5: Effect of Agitation Speeds on Betalains and Curcuminoids Extraction Yield during MS at $50 \%$ EtOH, SSR of 1/35 and Particle Size of $0.45 \mathrm{~mm}$

\subsection{Effect of Microwave Power on Extraction Yields during MAE for Betalains and Curcuminoids}

Figures $6(\mathrm{a}, \mathrm{b})$ depict the effect of microwave radiation on the extraction yield of betalains and curcuminoids. A low yield of $48.48 \%$ and $40.98 \%$ were recorded for betalains and curcuminoids at $136 \mathrm{~W}$ respectively. However, we observed a sharp rise in extraction yield of betalains and curcuminoids with $91.78 \%$ and $80.88 \%$ at $320 \mathrm{~W}$. At $320 \mathrm{~W}$, the cell rupture process is hastened due to the spontaneous rise in temperature and internal pressure inside the cells of matrices. However, at $136 \mathrm{~W}$, longer irradiation exposure time is required beyond $5 \mathrm{~min}$, owing to its low heat dissipation inside the microwave system, subsequently resulting in fewer rupturing of the plant cells. In most cases of the MAE, elevated temperatures result in greatest extraction efficiency. Nevertheless, care must be applied to the extraction of thermos labile pigments which might be denatured at high temperatures. Similar observation was also reported during the effect of microwave power on the MAE of flavonoids from Chinese herbs [19].

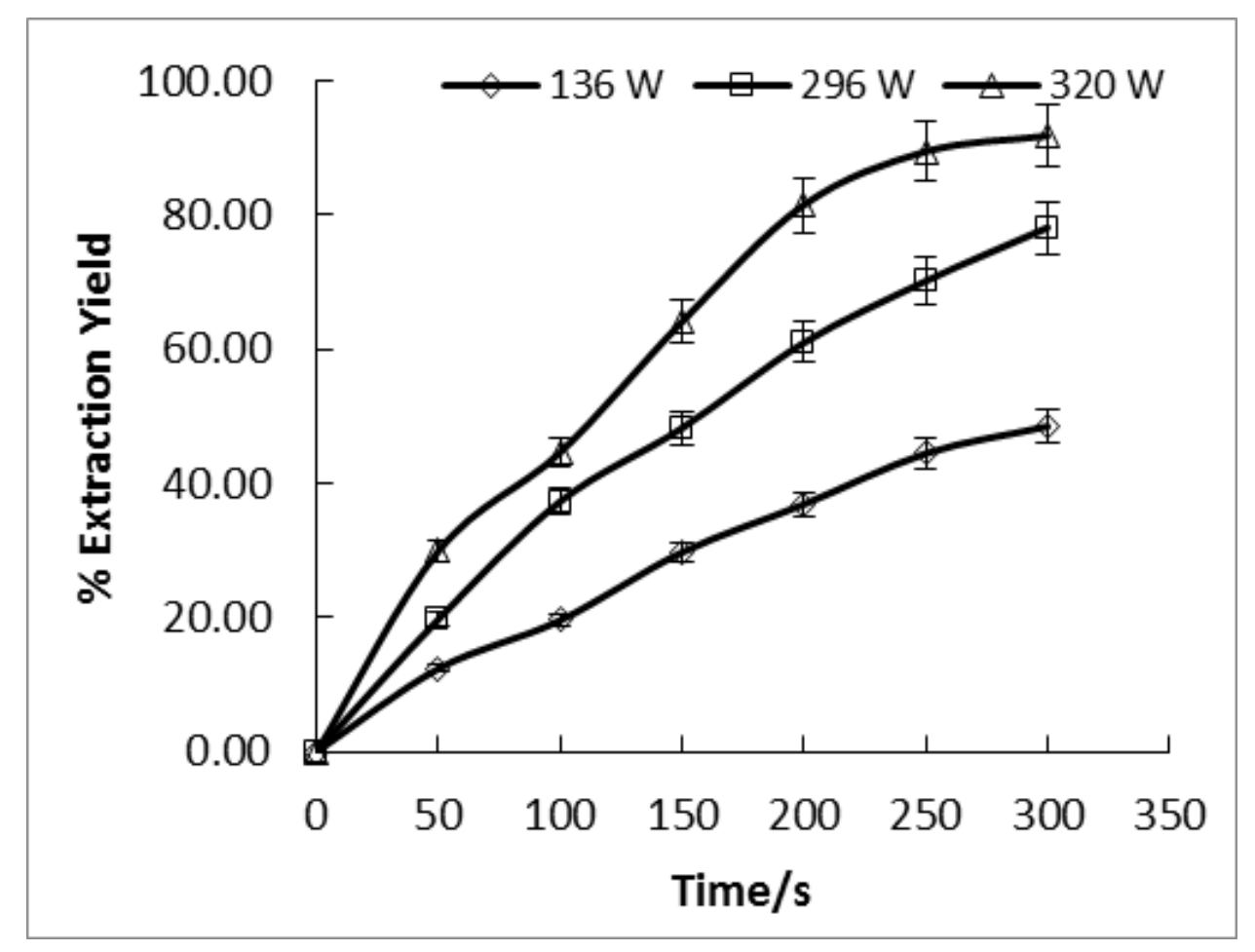




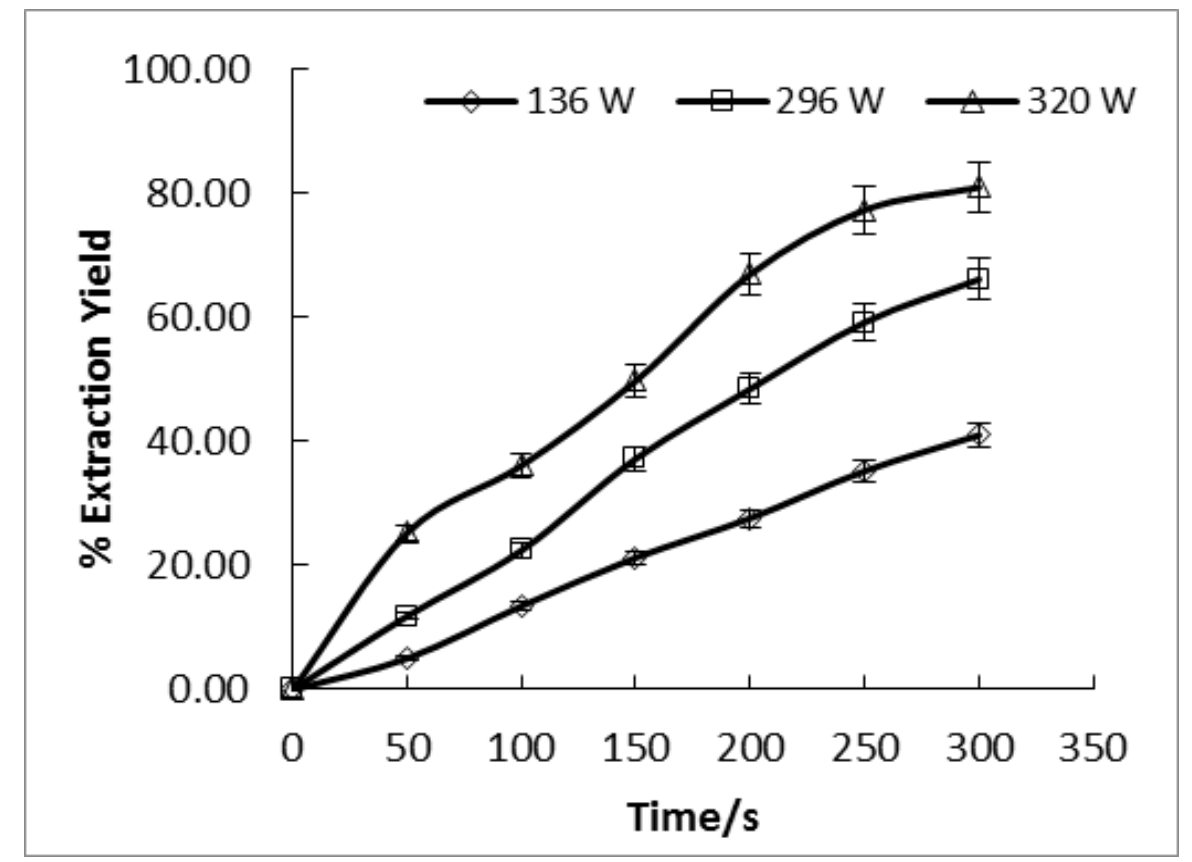

Fig.6: Effect of Microwave Power on Betalains and Curcuminoids Extraction Yield at $50 \%$ EtOH, SSR of 1/35 and Average Particle Size of $0.45 \mathrm{~mm}$

\subsection{Effect of Solid to Solvent Ratio on Extraction Yields during MS and MAE}

The solid to solvent ratio were set at $1 / 15,1 / 20,1 / 25,1 / 30,1 / 35$, under the extracting parameters of $50 \% \mathrm{EtOH}, 160 \mathrm{rpm}$ and 320 W. Figure $7(a, b)$ below represented the dye extraction yield on varied SSR for betalains using MS and MAE. Similar trends were observed for all SSR whereby the yields rose rapidly, followed by stabilisation. The amount of dye extracted by mass of solid beetroot increases in intensity from pale to deep colors as SSR was increased due to the availability of more biomass for extraction. During the classical method of betalains extraction, the maximum attainable yield was $69.55 \%$ for a SSR of $1 / 35$ whilst at a SSR of 1/15, the lowest yield of $36.10 \%$ was determined. Also depicted from the MAE of betalains, highest yields was achieved at SSR of $1 / 35$ corresponding to a yield of $89.64 \%$ and lowest yields of $48.96 \%$ at the SSR of $1 / 15$. Under the latter conditions, the solubility of dye in the solvent might restrict leaching of target solute as an elevated mass of solids can saturate the surrounding liquid thereby entailing a reduction in concentration gradient for solute and solvent interactions [13].

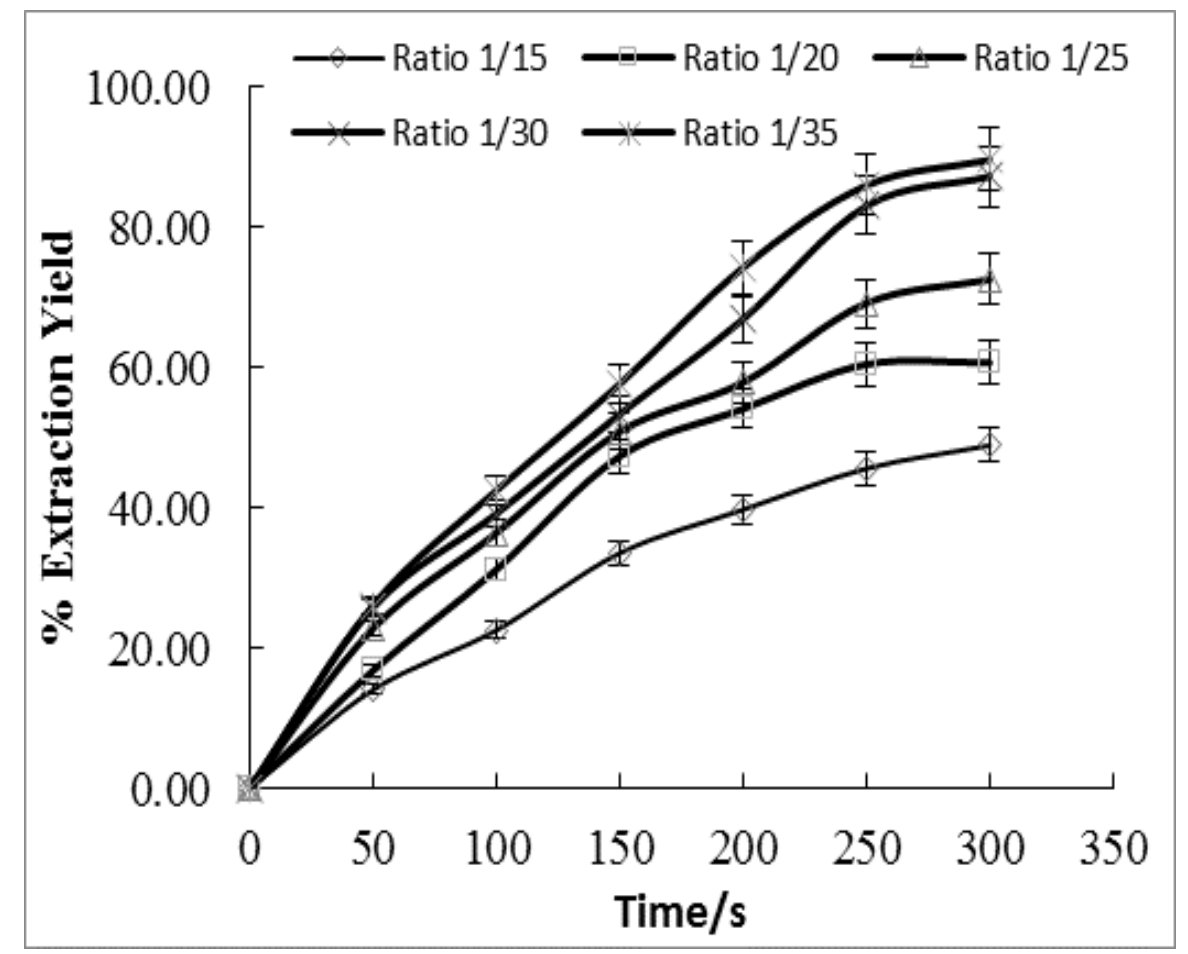




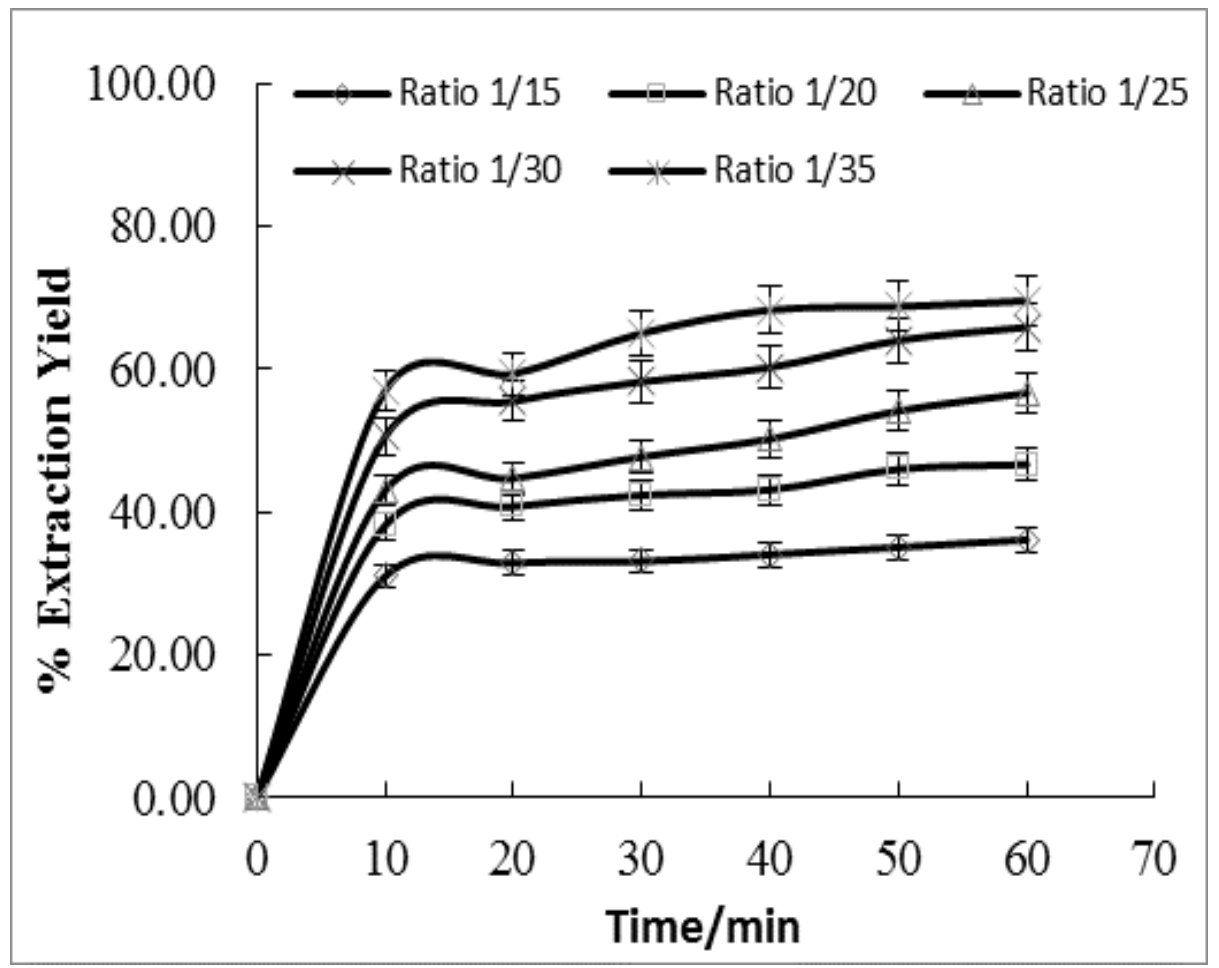

Fig.7: Effect of SSR on Betalains Extraction Yield at $50 \% \mathrm{EtOH}, 160 \mathrm{rpm}$ and $320 \mathrm{~W}$ during MS and MAE

On the other hand, Fig. 8(a, b) below represented the dye extraction yield on varied SSR for curcuminoids using MS and MAE. The curves revealed similar trends as for betalains for the various SSR on curcuminoids extraction yield. For the traditional extraction process, the highest and lowest curcuminoids extraction yield of $48.0 \%$ and $28.95 \%$ was achieved under the SSR of $1 / 35$ and 1/15 respectively. For the MAE, the highest and lowest yield of $79.73 \%$ and $39.67 \%$ were obtained at a SSR of $1 / 35$ and $1 / 15$ respectively.

At a SSR of 1/35, the concentration between the bulk solution and solutes is higher and overcoming of the dispersion forces between solvent molecules for curcuminoids interaction is significant [24]. Owing to a lower mass of materials, the contact surface area between turmeric and solvent were favorably increased, causing the rupture of cell walls and releasing of bioactive curcuminoids into the surrounding medium $[18,21]$.

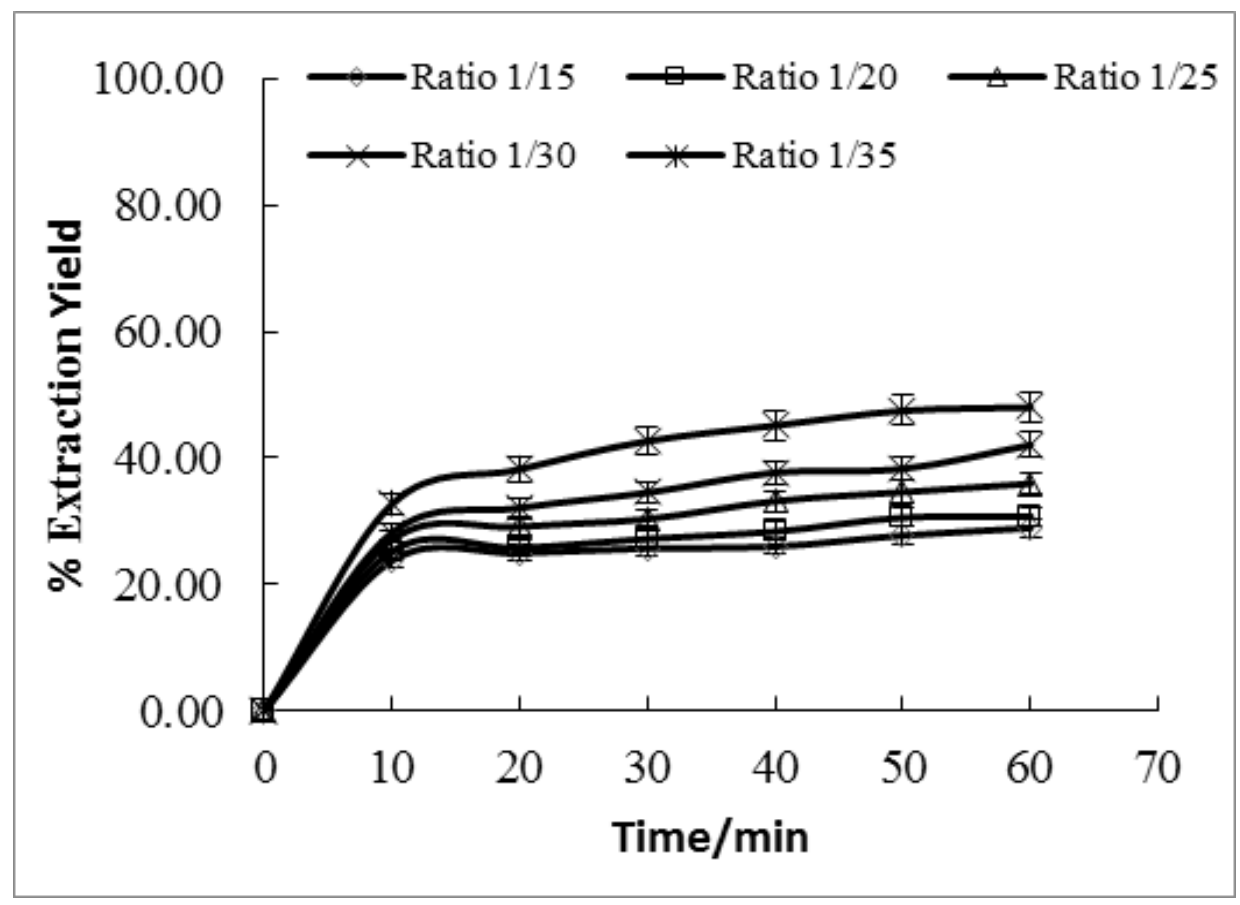




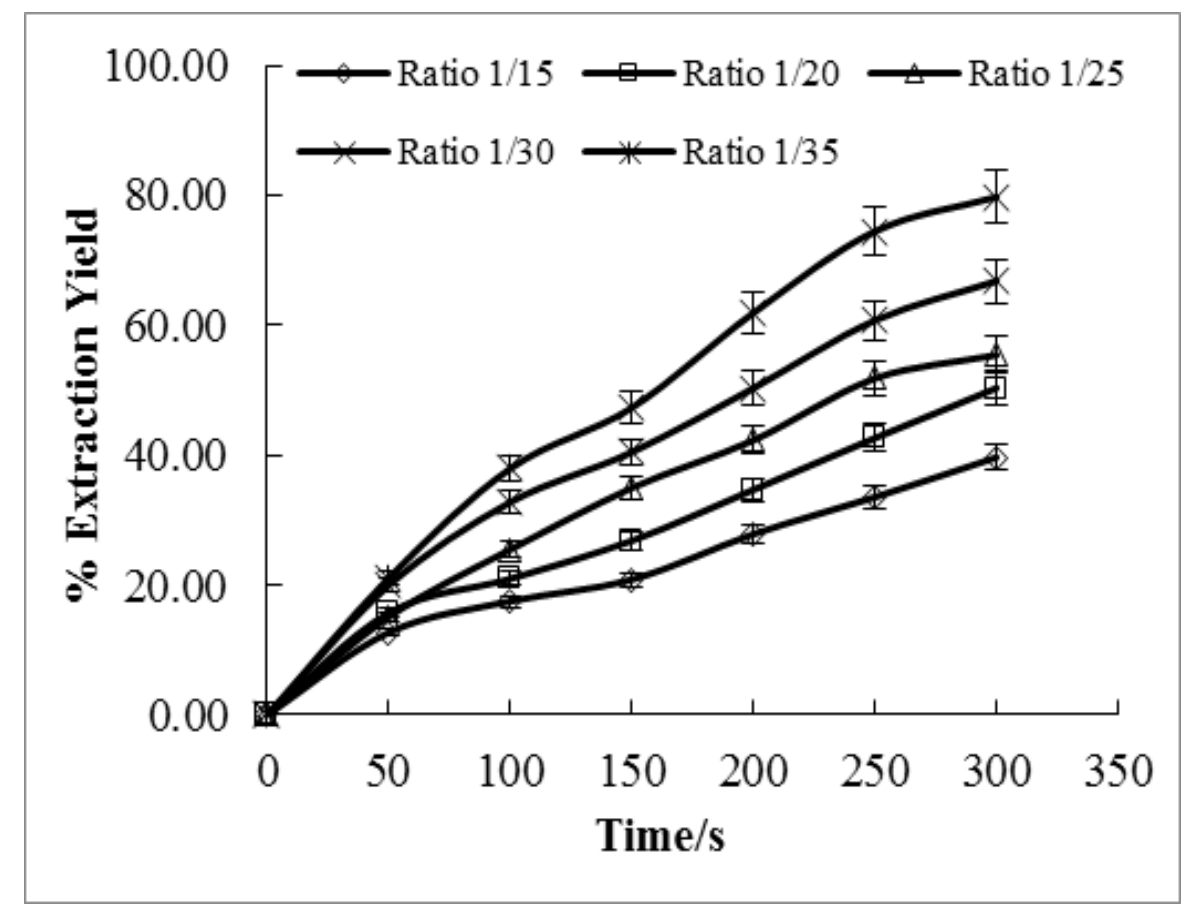

Fig. 8: Effect of SSR on Curcuminoids Extraction Yield at $50 \% \mathrm{EtOH}, 160 \mathrm{rpm}$ and $320 \mathrm{~W}$ during MS and MAE

\subsection{Effect of Particle Size on Extraction Yields during MS and MAE}

Figures 9 and 10 reveal the effect of particles sizes of $1.69 \mathrm{~mm}, 1.42 \mathrm{~mm}, 0.815 \mathrm{~mm}, 0.45 \mathrm{~mm}$ on the extraction yields of betalains and curcuminoids during the MS and MAE processes, whereby the highest extraction yield is recorded at the lowest particle size of $0.45 \mathrm{~mm}$. For the MS extraction process, the highest betalains and curcuminoids yield of $69.55 \%$ and $48.00 \%$ were respectively spotted at particle size of $0.45 \mathrm{~mm}$ whereas the lowest yield of $40.82 \%$ and $34.96 \%$ was observed at particle size $1.69 \mathrm{~mm}$ correspondingly. From the studied novel technique, during betalains and curcuminoids extraction similarly elevated yield was discerned at particle size $0.45 \mathrm{~mm}$, correlating a yield of $89.64 \%$ and $79.73 \%$ correspondingly whilst a decline yield of $53.29 \%$ and $48.19 \%$ for particle size $1.69 \mathrm{~mm}$. Less extractable dye yields were acquired from the coarse particles due to the lower surface contact area per unit weight and higher resistance to extraction as the solvent has to travel a longer distance to penetrate the sample matrices and solubilise the pigments. Thus, larger particles of $1.69 \mathrm{~mm}$ with smaller contact surface areas were more resistant to solvent entrance and dye diffusion thereby curbing the solutes extraction yields.

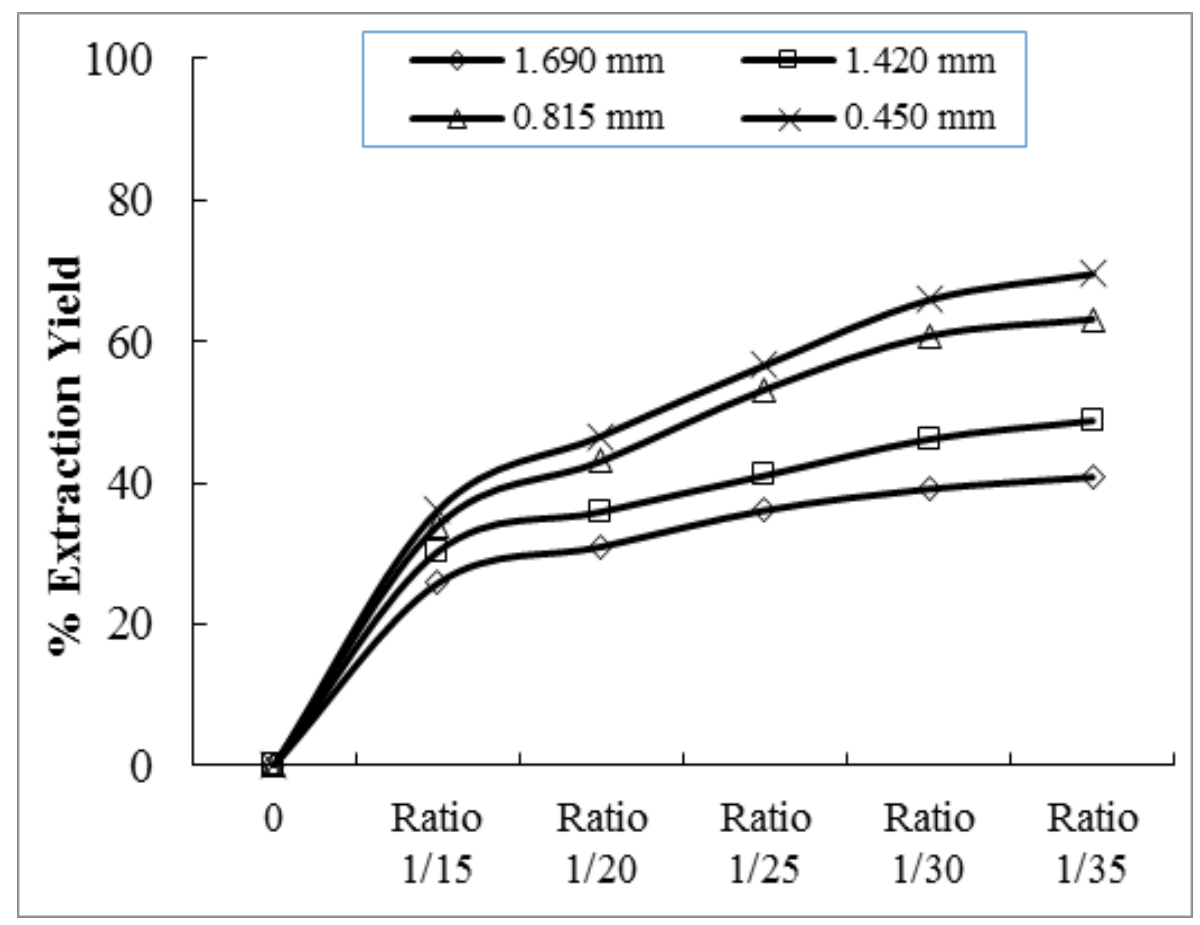




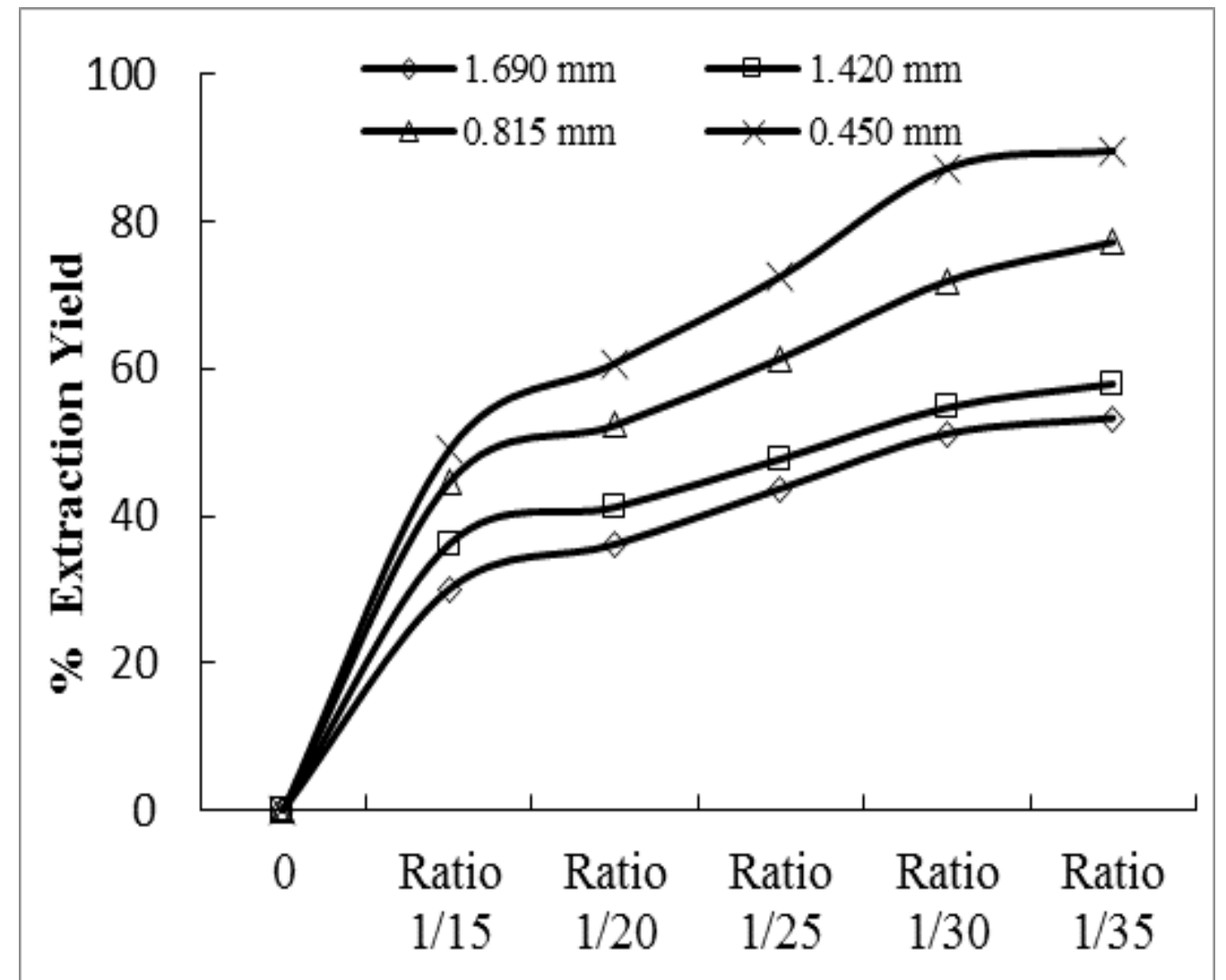

Fig. 9: Effect of Particle Size on Betalains Extraction Yield at different SSR during MS and MAE

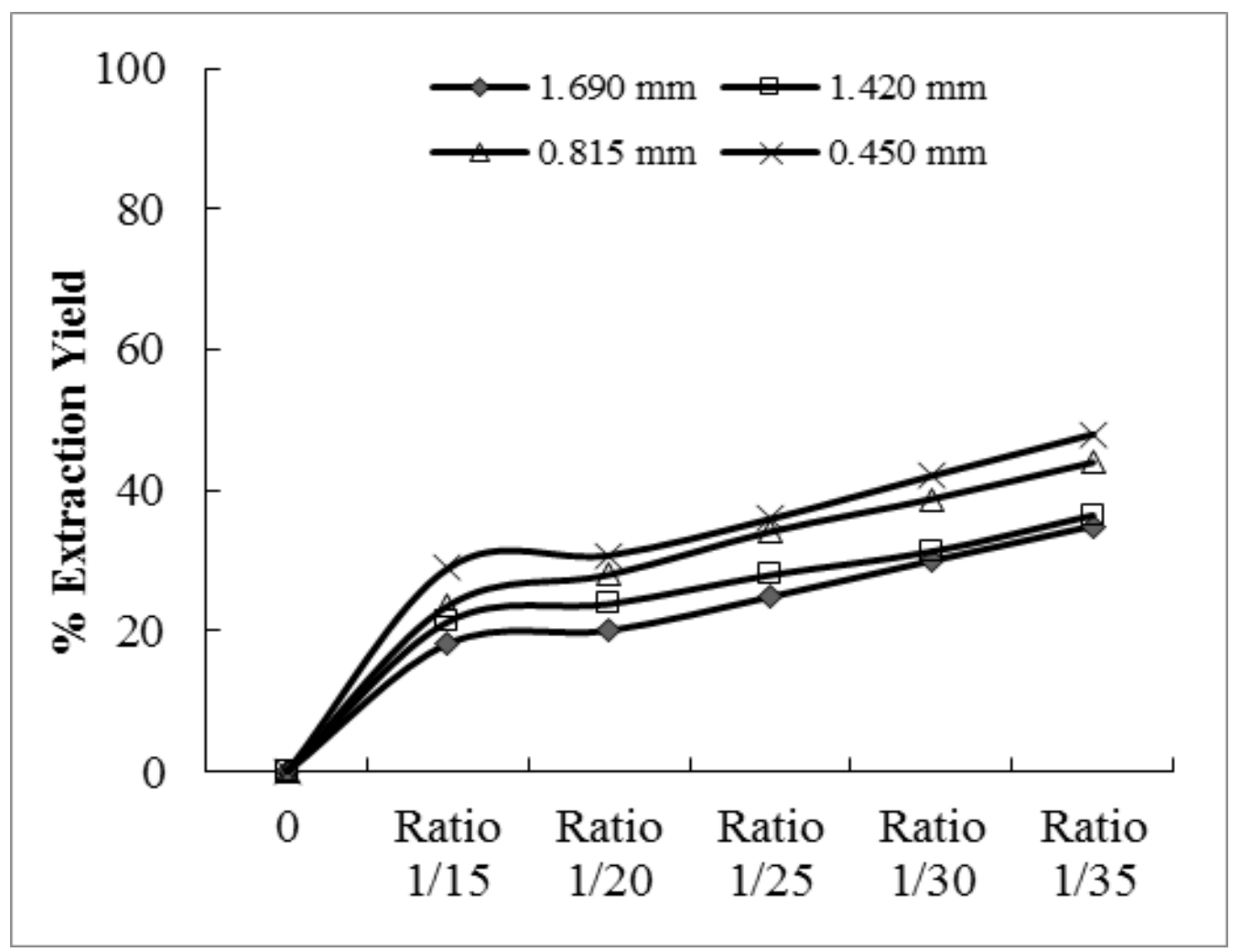




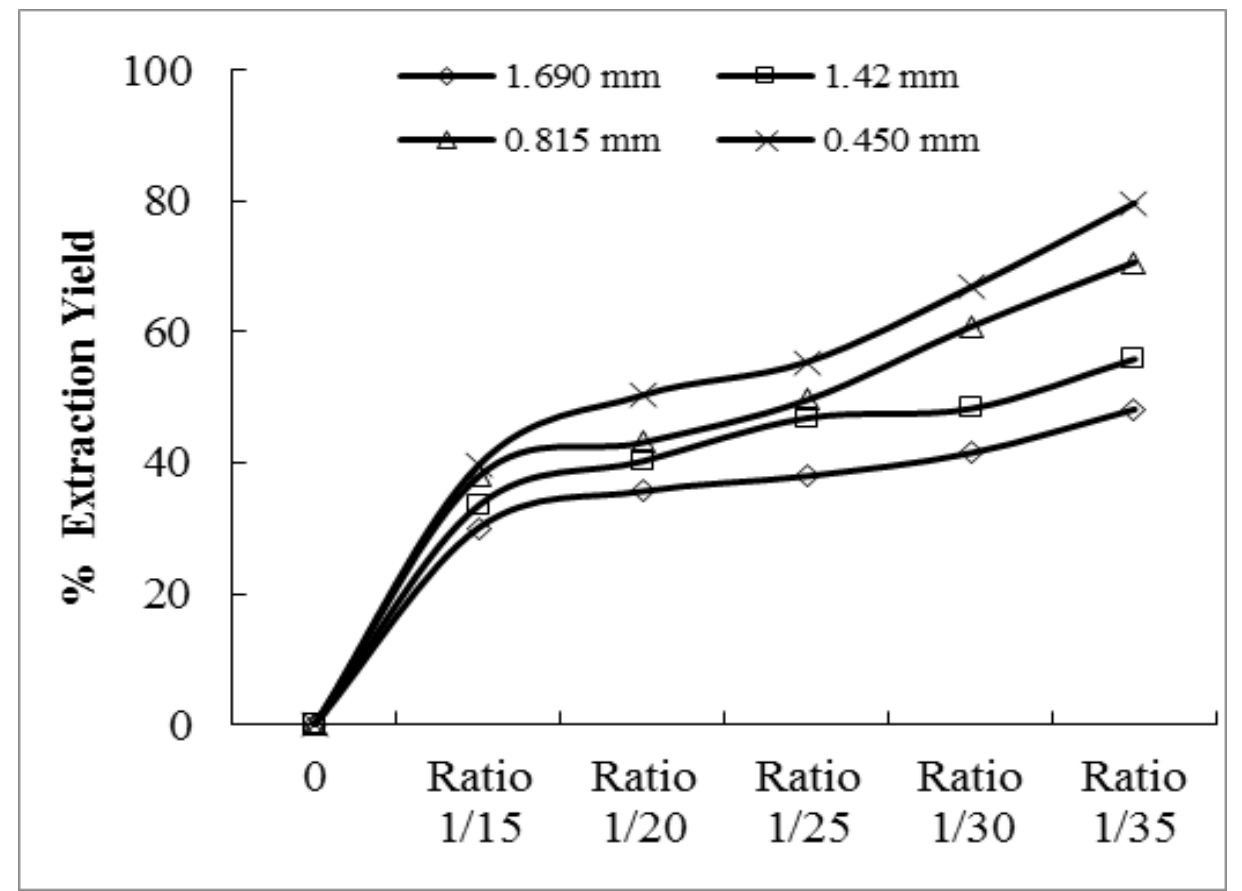

Fig. 10. Effect of Particle Size on Curcuminoids Extraction Yield at different SSR during MS and MAE

\subsection{Kinetic Models (KM) of Solid-Liquid Extraction}

The equations used for the KM in this study are tabulated in table 2 .

Table 2: KM applied for Extraction of Dyes

\begin{tabular}{|c|c|c|}
\hline $\begin{array}{l}\text { Linear } \\
\text { form of } \\
\text { equation }\end{array}$ & Plot & Symbols \\
\hline $\begin{array}{l}\frac{t}{c_{t}}=\mathrm{K}_{1}+\mathrm{K}_{2} \\
\mathrm{t} \\
\text { Where; } \\
\mathrm{K}_{1}=\frac{1}{B_{0}} \\
\mathrm{~K}_{2}=\frac{1}{C_{S}}\end{array}$ & $\begin{array}{l}\frac{t}{c_{t}} \\
\mathrm{v} / \mathrm{s} \mathrm{t}\end{array}$ & 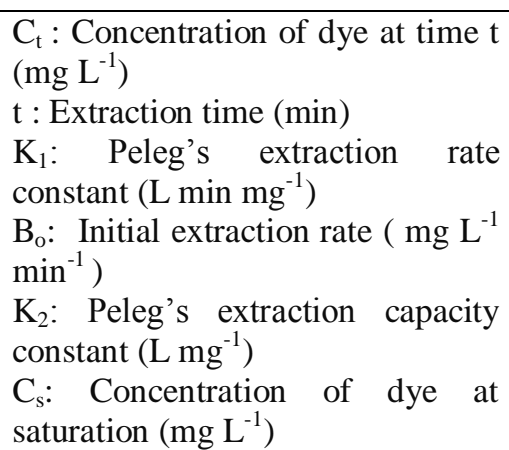 \\
\hline $\begin{array}{l}\mathrm{C}_{\mathrm{t}}=\frac{1}{\beta} \ln (\alpha \\
\beta)+\frac{1}{\beta} \ln \mathrm{t}\end{array}$ & $\begin{array}{l}\mathrm{C}_{\mathrm{t}} \\
\mathrm{v} / \mathrm{s} \\
\ln \mathrm{t}\end{array}$ & $\begin{array}{l}\mathrm{C}_{\mathrm{t}} \text { : Concentration of dye at time } \mathrm{t} \\
(\mathrm{mg} / \mathrm{L}) \\
\mathrm{t}: \text { Extraction time (min) } \\
\alpha: \text { Initial extraction rate }\left(\mathrm{mg} \mathrm{L}^{-1}\right. \\
\left.\min ^{-1}\right) \\
\beta: \text { Elovich's extraction rate } \\
\text { constant }\left(\mathrm{L} \mathrm{mg}^{-1}\right)\end{array}$ \\
\hline
\end{tabular}

\subsubsection{Peleg's Kinetic Model}

It was revealed that for all the SSR studied, the plots of $\mathrm{t} / \mathrm{Ct}$ versus $t$ resulted in linear functions, in agreement with the Peleg'kinetic model. The proposed model most aptly fit the experimental data which was confirmed by the high correlation coefficient. As discerned in tables 3 and 4 below, it could be pointed out that the model describes the kinetic behavior most appropriately to MS as an outcome of the higher $\mathrm{R}^{2}$ values yielded for this system. Irrespective of the extraction temperature, the highest $R^{2}$ values of 0.9974 and 0.9938 for betalains and curcuminoids extraction were respectively achieved in MS compared to MAE where the $\mathrm{R}^{2}$ values of 0.9815 and 0.9721 were obtained.

Table 3: Peleg's KM Parameters for Extraction of Betalains

\begin{tabular}{|c|c|c|c|c|c|}
\hline \multicolumn{6}{|c|}{ MS } \\
\hline $\begin{array}{l}\text { SS } \\
\text { R }\end{array}$ & $\begin{array}{l}\mathrm{K}_{1} \\
(\mathrm{~L} \text { min } \\
\left.\mathrm{mg}^{-1}\right)\end{array}$ & $\begin{array}{l}\mathbf{B}_{0} \\
\left(\mathrm{mg} \mathrm{L}^{-1}\right. \\
\left.\min ^{-1}\right)\end{array}$ & $\begin{array}{l}\mathbf{K}_{2} \\
\left(\mathbf{L} \mathrm{mg}^{-}\right. \\
\mathbf{1}^{-}\end{array}$ & $\begin{array}{l}\mathrm{C}_{\mathrm{s}}, \\
\left(\mathrm{mg} \mathrm{L}^{-}\right. \\
\mathbf{1}^{-}\end{array}$ & $\mathbf{R}^{2}$ \\
\hline $\begin{array}{l}1 / 1 \\
5\end{array}$ & 0.0608 & 16.45 & 0.0416 & 24.04 & $\begin{array}{l}0.997 \\
4\end{array}$ \\
\hline $\begin{array}{l}1 / 2 \\
0\end{array}$ & 0.0866 & 11.55 & 0.0425 & 23.53 & $\begin{array}{l}0.995 \\
5\end{array}$ \\
\hline $\begin{array}{l}1 / 2 \\
5\end{array}$ & 0.1452 & 6.89 & 0.0438 & 22.83 & $\begin{array}{l}0.987 \\
5\end{array}$ \\
\hline $\begin{array}{l}1 / 3 \\
0\end{array}$ & 0.1189 & 8.41 & 0.045 & 22.22 & $\begin{array}{l}0.993 \\
4\end{array}$ \\
\hline $\begin{array}{l}1 / 3 \\
5\end{array}$ & 0.1124 & 8.89 & 0.0503 & 19.88 & $\begin{array}{l}0.993 \\
8\end{array}$ \\
\hline \multicolumn{6}{|c|}{ MAE } \\
\hline $\begin{array}{l}1 / 1 \\
5\end{array}$ & 4.7785 & 0.209 & 0.0142 & 70.42 & $\begin{array}{l}0.966 \\
7\end{array}$ \\
\hline $\begin{array}{l}1 / 2 \\
0\end{array}$ & 4.739 & 0.211 & 0.015 & 66.67 & $\begin{array}{l}0.887 \\
9\end{array}$ \\
\hline $\begin{array}{l}1 / 2 \\
5\end{array}$ & 4.744 & 0.211 & 0.0183 & 54.64 & $\begin{array}{l}0.981 \\
5\end{array}$ \\
\hline $\begin{array}{l}1 / 3 \\
0\end{array}$ & 5.6562 & 0.177 & 0.0155 & 64.52 & $\begin{array}{l}0.907 \\
1\end{array}$ \\
\hline $\begin{array}{l}1 / 3 \\
5\end{array}$ & 6.1061 & 0.164 & 0.0178 & 56.179 & $\begin{array}{l}0.959 \\
0\end{array}$ \\
\hline
\end{tabular}


With regards to Peleg's equations, in both extraction methods it could be perceived that the initial extraction rates, $\mathrm{B}_{\mathrm{o}}$ being the reciprocal of Peleg's extraction rate constant, $K_{1}$ tend to decline with diminishing SSR. The decrease in extraction rate might be elucidated by the fact that at low SSR value the slow diffusion stage was possibly the dominant one implying that the rapid initial washing stage occurred spontaneously. Consequently, the initial extraction rate was related to the fast washing period, indicating that the washing stage was still triggering at high SSR.

Table 4: Peleg's KM Parameters for Extraction of Curcuminoids

\begin{tabular}{|c|c|c|c|c|c|}
\hline \multicolumn{6}{|c|}{ MS } \\
\hline $\begin{array}{l}\text { SS } \\
\text { R }\end{array}$ & $\begin{array}{l}\mathrm{K}_{1} \\
(\mathbf{L} \text { min } \\
\left.\mathbf{m g}^{-1}\right)\end{array}$ & $\begin{array}{l}\mathbf{B}_{\mathbf{0}} \\
\left(\mathrm{mg} \mathrm{L}^{-1}\right. \\
\left.\text { min }^{-1}\right)\end{array}$ & $\begin{array}{l}\mathrm{K}_{2} \\
\left(\mathbf{L} \mathrm{mg}^{-}\right. \\
\left.\mathrm{l}^{\prime}\right)\end{array}$ & $\begin{array}{l}\mathrm{C}_{\mathrm{s}}, \\
\left(\mathrm{mg} \mathrm{L}^{-}\right. \\
\left.{ }^{\prime}\right)\end{array}$ & $\mathbf{R}^{2}$ \\
\hline $\begin{array}{l}1 / 1 \\
5\end{array}$ & 0.2202 & 4.54 & 0.1041 & 9.60 & $\begin{array}{l}0.993 \\
5\end{array}$ \\
\hline $\begin{array}{l}1 / 2 \\
0\end{array}$ & 0.3119 & 3.21 & 0.1281 & 7.81 & $\begin{array}{l}0.993 \\
0\end{array}$ \\
\hline $\begin{array}{l}1 / 2 \\
5\end{array}$ & 0.4341 & 2.30 & 0.1371 & 7.29 & $\begin{array}{l}0.990 \\
0\end{array}$ \\
\hline $\begin{array}{l}1 / 3 \\
0\end{array}$ & 0.5801 & 1.72 & 0.1418 & 7.05 & $\begin{array}{l}0.983 \\
8\end{array}$ \\
\hline $\begin{array}{l}1 / 3 \\
5\end{array}$ & 0.5165 & 1.94 & 0.1402 & 7.133 & $\begin{array}{l}0.990 \\
3\end{array}$ \\
\hline \multicolumn{6}{|c|}{ MAE } \\
\hline $\begin{array}{l}1 / 1 \\
5\end{array}$ & 12.492 & 0.080 & 0.0401 & 24.9 & $\begin{array}{l}0.766 \\
0\end{array}$ \\
\hline $\begin{array}{l}1 / 2 \\
0\end{array}$ & 13.782 & 0.072 & 0.0398 & 25.1 & $\begin{array}{l}0.748 \\
8\end{array}$ \\
\hline $\begin{array}{l}1 / 2 \\
5\end{array}$ & 15.283 & 0.065 & 0.0391 & 25.6 & $\begin{array}{l}0.972 \\
1\end{array}$ \\
\hline $\begin{array}{l}1 / 3 \\
0\end{array}$ & 13.814 & 0.072 & 0.0459 & 21.8 & $\begin{array}{l}0.948 \\
1\end{array}$ \\
\hline $\begin{array}{l}1 / 3 \\
5\end{array}$ & 15.187 & 0.066 & 0.0368 & 27.2 & $\begin{array}{l}0.945 \\
7\end{array}$ \\
\hline
\end{tabular}

\subsubsection{Elovich's Kinetic Model}

The extraction of dyes can be expressed in a linear form according to Elovich's model. It was assumed that the leaching rates are reduced exponentially with the rise in extraction yields. MS extraction for both betalains and curcuminoids effected in lower $\mathrm{R}^{2}$ values compared to Peleg's kinetic model. Conversely, the highest value of $\mathrm{R}^{2}$ was obtained particularly during MAE for both hues. As it can be seen in tables 5 and 6 below, the kinetic modeled parameters evaluated also impacted the extraction process significantly. The intercept and slope values could be derived from the linear plots. The determination of Elovich's extraction rate constant; $\beta$ is related to the time required to achieve maximum extraction of dyes. It was observed that the extraction rate constant fluctuated according to the model. The minor change in the extraction constant could be discerned owing to the loss of dye during the initial preparation stage [25].
The model appeared to be valid in describing experimental data with initial extraction rate, $\alpha$. The initial extraction rate is inferior, at reduced SSR. This implied that the extraction behavior can be defined by the Elovich's model wherein the extraction curve can be differentiated in the first as well as the slow extraction stage. At the washing step, the quick penetration of the fresh solvent and dissolution of the easily available molecules at the surface formed a high concentration gradient into the solid, which enhanced the mass transfer [26, 27]. Since the washing period occurred instantly at the lower SSR, the diffusion action was persistent, thus initiating a drop in the extraction rate.

Table 5: Elovich's KM Parameters for Extraction of Betalains

\begin{tabular}{|c|c|c|c|c|c|}
\hline \multirow{2}{*}{\multicolumn{6}{|c|}{ MS }} \\
\hline & & & & & \\
\hline $\begin{array}{l}\text { SS } \\
\text { R }\end{array}$ & $1 / \boldsymbol{\beta}$ & $\begin{array}{l}\beta \\
\left(\mathbf{L} \mathrm{mg}^{-}\right. \\
\left.{ }_{1}\right)\end{array}$ & $\begin{array}{l}1 / \beta \ln (\alpha \\
\beta)\end{array}$ & $\begin{array}{ll}\alpha & \\
\left(\mathbf{m g}^{-1}\right. & \mathbf{L}^{-1} \\
\left.\min ^{-1}\right) & \end{array}$ & $\mathbf{R}^{2}$ \\
\hline $\begin{array}{l}1 / 1 \\
5\end{array}$ & $\begin{array}{l}1.761 \\
9\end{array}$ & 0.568 & 16.467 & 20182 & $\begin{array}{l}0.940 \\
5\end{array}$ \\
\hline $\begin{array}{l}1 / 2 \\
0\end{array}$ & $\begin{array}{l}2.357 \\
2\end{array}$ & 0.424 & 13.401 & 694 & $\begin{array}{l}0.951 \\
4\end{array}$ \\
\hline $\begin{array}{l}1 / 2 \\
5\end{array}$ & $\begin{array}{l}3.031 \\
5\end{array}$ & 0.329 & 9.4592 & 69 & $\begin{array}{l}0.889 \\
6\end{array}$ \\
\hline $\begin{array}{l}1 / 3 \\
0\end{array}$ & 2.792 & 0.358 & 10.194 & 108 & $\begin{array}{l}0.973 \\
5\end{array}$ \\
\hline $\begin{array}{l}1 / 3 \\
5\end{array}$ & $\begin{array}{l}1.922 \\
5\end{array}$ & 0.52 & 11.429 & 734 & $\begin{array}{l}0.891 \\
4\end{array}$ \\
\hline \multicolumn{6}{|c|}{ MAE } \\
\hline $\begin{array}{l}1 / 1 \\
5\end{array}$ & $\begin{array}{l}13.51 \\
2\end{array}$ & 0.074 & -44.933 & 0.486 & $\begin{array}{l}0.980 \\
2\end{array}$ \\
\hline $\begin{array}{l}1 / 2 \\
0\end{array}$ & $\begin{array}{l}13.21 \\
4\end{array}$ & 0.0757 & -43.611 & 0.487 & $\begin{array}{l}0.981 \\
8\end{array}$ \\
\hline $\begin{array}{l}1 / 2 \\
5\end{array}$ & 11.5 & 0.0869 & -36.937 & 0.463 & $\begin{array}{l}0.981 \\
5\end{array}$ \\
\hline $\begin{array}{l}1 / 3 \\
0\end{array}$ & 11.95 & 0.0837 & -40.096 & 0.417 & $\begin{array}{l}0.950 \\
3\end{array}$ \\
\hline $\begin{array}{l}1 / 3 \\
5\end{array}$ & $\begin{array}{l}10.70 \\
8\end{array}$ & 0.0934 & -35.719 & 0.381 & $\begin{array}{l}0.971 \\
5\end{array}$ \\
\hline
\end{tabular}

Table 6: Elovich's KM Parameters for Extraction of Curcuminoids

\begin{tabular}{|c|c|c|c|c|c|}
\hline \multicolumn{6}{|l|}{ MS } \\
\hline $\begin{array}{l}\text { SS } \\
\text { R }\end{array}$ & $1 / \beta$ & $\begin{array}{l}\beta \\
\left(\mathbf{L} \mathrm{mg}^{-}\right. \\
\left.{ }_{1}\right)\end{array}$ & $\begin{array}{l}1 / \beta \ln (\alpha \\
\beta)\end{array}$ & $\begin{array}{l}\alpha \\
\left(\mathbf{m g}^{-1}\right)\end{array} \mathbf{L}^{-1}$ & $\mathbf{R}^{2}$ \\
\hline $\begin{array}{l}1 / 1 \\
5\end{array}$ & $\begin{array}{l}0.881 \\
9\end{array}$ & 1.134 & 5.7323 & 587 & $\begin{array}{l}0.869 \\
6\end{array}$ \\
\hline $\begin{array}{l}1 / 2 \\
0\end{array}$ & $\begin{array}{l}0.824 \\
5\end{array}$ & 1.213 & 4.1963 & 134 & $\begin{array}{l}0.871 \\
3\end{array}$ \\
\hline $\begin{array}{l}1 / 2 \\
5\end{array}$ & $\begin{array}{l}1.003 \\
8\end{array}$ & 0.996 & 2.9303 & 19 & $\begin{array}{l}0.939 \\
1\end{array}$ \\
\hline $\begin{array}{l}1 / 3 \\
0\end{array}$ & 1.218 & 0.821 & 1.7733 & 5 & $\begin{array}{l}0.960 \\
5\end{array}$ \\
\hline $\begin{array}{l}1 / 3 \\
5 \\
\end{array}$ & $\begin{array}{l}1.277 \\
4 \\
\end{array}$ & 0.782 & 1.7096 & 5 & $\begin{array}{l}0.993 \\
9 \\
\end{array}$ \\
\hline
\end{tabular}




\begin{tabular}{|l|l|l|l|l|l|}
\hline $1 / 1$ & 4.842 & 0.207 & -15.796 & 0.186 & $\begin{array}{l}0.891 \\
5\end{array}$ \\
3 & & & & 5 \\
\hline $1 / 2$ & 4.696 & 0.213 & -15.553 & 0.171 & 0.918 \\
0 & 5 & & & & \\
\hline $1 / 2$ & 4.607 & 0.217 & -15.573 & 0.157 & 0.970 \\
5 & 3 & & & & 2 \\
\hline $1 / 3$ & 4.338 & 0.23 & -14.203 & 0.164 & 0.960 \\
0 & 9 & & & & 9 \\
\hline $1 / 3$ & $\begin{array}{l}4.763 \\
5\end{array}$ & 0.209 & -16.184 & 0.159 & $\begin{array}{l}0.965 \\
8\end{array}$ \\
\hline
\end{tabular}

\section{CONCLUSION}

The results clearly shows that MAE is an efficient process for the isolation of dyes from the studied biomass as it reduces the extraction time drastically compared to the classical system. The variation of solvent mixture, agitation speed of magnetic stirrer, microwave power, solid to solvent ratio and particle size of the plant were studied to determine the highest extraction yield of betalains and curcuminoids. The analysis revealed that the optimum conditions were obtained at $50 \%$ aqueous ethanol, agitation speed of 160 $\mathrm{rpm}$, microwave power of $320 \mathrm{~W}$, particle size of $0.45 \mathrm{~mm}$ and a SSR of 1/35. Besides, Peleg's and Elovich's mathematical models were evaluated to understand and describe the kinetics of natural dyes extraction. Peleg's kinetic model was mostly valid in describing the extraction kinetics particularly to MS while Elovich kinetic model fitted the experimental data of MAE more accurately. It could be ultimately deduced that the use of MAE for the leaching of pigmented solutes, is considered as a viable technique for enhancing a slow process and most essentially requiring fewer energy consumption, with high extract quality.

\section{REFERENCES}

[1] Gilbert, K.G. and Cooke, D.T., 2001. Dyes from plants: Past usage, present understanding and potential, Journal of Plant Growth Regulation, 34, pp. 57-69.

[2] Hunger, K., 2003. Industrial dyes: Chemistry, Properties, Applications, Wiley-Vch Verlag GmbH \& Co. KGaA, ISBN 35-27304-26-6, Darmstadt, Germany.

[3] Bechtold, T. and Mussak, R., 2009. Handbook of natural colorants, John Wiley \& Sons, ISBN 978-0470-51199-2, West Sussex, England.

[4] Ibrahim, N.A., Gamal, A.R., Gouda, M. and Mahrous, F., 2010. A new approach for natural dyeing and functional finishing of cotton cellulose, Carbohydrate Polymers, 82, pp. 1205-1211.

[5] Prabhu, K.H., 2012. Plant based natural dyes and mordants: A review. Journal of Natural Product Plant Resources, 2012, 2 (6), pp. 649-664.

[6] Gasztonyi, M.N., Daood, H., Hajos, M.T. and Biacs, P., 2001. Comparison of red beet (Beta vulgaris var. conditiva) varieties on the basis of their pigment components. Journal of the Science of Food and Agriculture, 81, pp. 932-933.
Kapadia, G.J., Tokuda, H., Konoshima, T. and Nishino, H., 1996. Chemoprevention of lung and skin cancer by Beta vulgaris (Beet) root extract. Cancer letters, 100(1-2), pp. -214.

Venkatesh, M.S. and Raghavan, G.S.V., 2004. An Overview of Microwave Processing and Dielectric Properties of Agri-food Materials. Biosystems Engineering 88(1), pp. 1-18.

Richter, R. C., Link, D. and Kingston, H. M., 2001. Microwave-enhanced chemistry. Analytical Chemistry 73, pp. 30A-37A.

[10] Zhang, L. and Liu, Z., 2008. Optimization and comparison of ultrasound/microwave assisted extraction (UMAE) and ultrasonic assisted extraction (UAE) of lycopene from tomatoes. Ultrasonics Sonochemistry, 15, pp. 731-737.

[11] Spigno, G., Tramelli, L., and De Faveri, D.M., 2007. Effects of extraction time, temperature and solvent on concentration and antioxidant activity of grape marc phenolics. Journal of Food Engineering, 81, pp. 200-208.

[12] Pinelo, M., Sineiro, J. and Nunez, M. J., 2006. Mass transfer during continuous solid-liquid extraction of antioxidants from grape by-products. Journal of Food Engineering 77(1), pp. 57-63.

[13] Rakotondramasy-Rabesiaka, L., Havet, J.L., Porte, C. and Fauduet, H., 2009. Solid-liquid extraction of protopine from Fumariaofficinalis L. - Analysis determination, kinetic reaction and model building. Separation and Purification Technology, 54 (2), pp. 253-261.

[14] Xiao, X., Song, W., Wang, J. and Li, G., 2012. Microwave-assisted extraction performed in low temperature and in the extraction of labile compounds in food samples. Analytica Chimica Acta 712 (0), pp. 85-93.

[15] Alupului, A., 2012. Microwave extraction of active principles from medicinal plants. U.P.B. Science Bulletin, Series B 74(2).

[16] Chan, C.H., Yusoff, R., Ngoh, G.-C. and Kung, F.W.L., 2011. Microwave-assisted extractions of active ingredients from plants. Journal of Chromatogry A, 1218 (37), pp. 6213-6225.

[17] Sinha, K., Saha, P.D. and Datta, S., 2012A. Response surface optimization and artificial neural network modeling of microwave assisted natural dye extraction from pomegranate rind. Industrial Crops and Products 37, 408-414.

[18] Guo, Z., Jin, Q., Fan, G., Duan, Y., Qin, C., and Wen, M., 2001. Microwave-assisted extraction of effective constituents from a Chinese herbal medicine Radix puerariae. Analytica Chimica Acta, 436, pp. 41-47.

[19] Sivakumar, V., Anna, J.L., Vijayeeswarri, J. and Swaminathan, G., 2009a. Ultrasound assisted enhancement in natural dye extraction from beetroot for industrial applications and natural dyeing of leather. Ultrasonics Sonochemistry 16, 782-789. 
[20] Bagchi. A., 2012. Extraction of curcumin. Journal of Environmental Science, Toxicology and Food Technology, 1(3), pp. 1-16.

[21] Zeng, H., Wang, Y., Kong, J., Nie, C. and Yuan, Y., 2010. Ionic liquid-based microwave-assisted extraction of rutin from Chinese medicinal plants. Talanta, 83, pp. 582-590.

[22] Wongkittipong, R., Prat, L., Damronglerd, S. and Gourdon, C., 2004. Solid-liquid extraction of andrographolide from plants - experimental study, kinetic reaction and model. Separation and Purification Technology, 40 (2), pp. 147-154.

[23] Bird, R.B., Stewart, W.E. and Lightfoot, E.N., 2006. Transport Phenomena. Wiley, New York.

[24] Qu, W., Pan, Z. and Ma, H., 2010. Extraction modeling and activities of antioxidants from pomegranate marc. Journal of Food Engineering, 99 (1), pp. 16-23.

[25] Moubarik, A., El-Belghiti, K. and Vorobiev, E., 2011. Kinetic model of solute aqueous extraction from Fennel (Foeniculum vulgare) treated by pulsed electric field, electrical discharges and ultrasonic irradiations. Food and Bioproducts Processing, 89 (4), pp. 356-361.

[26] Bucic-Kojic, A., Planinic, M., Tomas, S., Bilic, M. and Velic, D., 2007. Study of solid-liquid extraction kinetics of total polyphenols from grape seeds. Journal of Food Engineering, 81 (1), pp. 236-242.

[27] Cacace, J.E. and Mazza, G., 2003. Mass transfer process during extraction of phenolics compounds from milled berries. Journal of Food Engineering 59 (4), pp. 379-389. 